\title{
Avances de investigación para la propagación vegetativa por cultivo in vitro de Myrciaria dubia (H.B.K.) Mc Vaugh "camu camu"
}

\author{
[Research advances for vegetative propagation by in vitro culture of Myrciaria \\ dubia (H.B.K.) Mc Vaugh "camu camu"]
}

Sergio Pinedo-Freyre*, Sixto Imán-Correa \& Eloiza Celis-Morey

Instituto Nacional de Innovación Agraria, Calle San Roque № 209, San Juan Bautista, Maynas, Loreto, Perú.

*e-mail: spinedo@inia.gob.pe

\begin{abstract}
Resumen
El trabajo fue realizado en el Laboratorio de Cultivo de Tejidos Vegetales de la Estación Experimental Agraria San Roque, del INIA Loreto con el objetivo de establecer un protocolo para el cultivo in vitro de segmentos nodales de camu camu" Myrciaria dubia " (H.B.K) Mc Vaugh. La fuente de material vegetal, fueron ramas de la parte apical de plantas adultas de la Colección Nacional de camu camu del INIA Loreto, se realizaron ensayos de desinfección, medios de cultivo y diferentes concentraciones de hormonas. El medio de cultivo utilizado fue Murashige \& Skoog, MS 1962; más factores constantes $20 \mathrm{~g} / \mathrm{L}$ sacarosa, 0,25 g/L carbón activado, $7 \mathrm{~g} / \mathrm{L}$ agar y pH 5,7. Los tratamientos de desinfección que presentaron los mayores porcentajes $(100 \%)$ de supervivencia de segmentos nodales, fueron: Hipoclorito 0,3\% + Chupadera $1 \mathrm{~g} / \mathrm{L}$ en M\&S, M\&S $1 / 2$ y M\&S + AIB y Hipoclorito $0,5 \%$ + Chupadera $2 \mathrm{~g} / \mathrm{L}$ en $M \& S$, M\&S $1 / 2$ y M\&S + AIB. El mejor medio de cultivo para la fase de crecimiento in vitro fue $\mathrm{M} \& \mathrm{~S}+1,5 \mathrm{mg} / \mathrm{L} \mathrm{GA} 3+10 \mathrm{mg} / \mathrm{L} \mathrm{AIA}$ con $72 \%$ de supervivencia a los 45 días después de la siembra. El mejor medio de cultivo para la fase de multiplicación fue $M \& S+2,5 \mathrm{mg} / \mathrm{L}$ BAP $+0,1 \mathrm{mg} / \mathrm{L}$ ANA con $80 \%$ de supervivencia a los 30 días después del subcultivo.
\end{abstract}

Palabras clave: camu camu, segmento nodal, cultivo in vitro, fitohormonas.

\begin{abstract}
The objective of this study was to establish a protocol for the in vitro culture of nodal segments Myrciaria dubia "camu camu" (HBK) Mc Vaugh. The source of the material, were branches of the apical part of adult plants of the National Collection of camu camu INIA Loreto. For cultivation in vitro assays were performed disinfection, culture media and different concentrations of hormones, in the Laboratory of Plant Tissue Culture, INIA-Loreto. The culture medium used was Murashige \& Skoog, 1962 MS; most constant factors 20 $\mathrm{g} / \mathrm{L}$ sucrose, $0.25 \mathrm{~g} / \mathrm{L}$ activated carbon, $7 \mathrm{~g} / \mathrm{L}$ agar, $\mathrm{pH}$ 5.7. Disinfection treatments that had higher survival rates in the nodal segments were; hypochlorite $0.3 \%+$ Chupadera $1 \mathrm{~g} / \mathrm{L}$, in M\&S, M\&S $1 / 2$ and M\&S + AIB and hypochlorite $0.5 \%$ + Chupadera $2 \mathrm{~g} / \mathrm{L}$, in M\&S, M\&S and M\&S $1 / 2$ + AIB, with $100 \%$ in both treatments. The best medium for the growth phase in vitro is M\&S $+1.5 \mathrm{mg} / \mathrm{L} \mathrm{GA3}+10 \mathrm{mg} / \mathrm{L} \mathrm{IAA}, 72 \%$ survival at 45 days after sowing. The best medium for the multiplication phase is M\&S $+2.5 \mathrm{mg} / \mathrm{L} \mathrm{BAP}+0.1 \mathrm{mg} / \mathrm{L} \mathrm{NAA}$, $80 \%$ survival at 30 days after subculture.
\end{abstract}

Keywords: camu camu, nodal segment, in vitro culture, phytohormones. 


\section{INTRODUCCIÓN}

El camu camu Myrciaria dubia (H.B.K.) Mc Vaugh, es una especie frutal nativa de la Amazonía peruana que crece en forma silvestre en orillares inundables y ha despertado gran interés en la agroindustria por su alto contenido en ácido ascórbico, alrededor de 2 g/100 gramos de pulpa (Pinedo, 2010).

El Instituto Nacional de Innovación Agraria INIA, a través de la Estación Experimental Agraria "San Roque", ha venido generando conocimiento para la domesticación del camu camu desde 1972; el año 1988, instala una colección de germoplasma constituida por 43 accesiones 0 muestras representativas colectadas de las poblaciones naturales; de la región Loreto en el Campo Experimental "Muyuy", bajo condiciones de suelos aluviales inundables, con una réplica en el Campo Experimental "El Dorado", en condiciones de suelos no inundables o de tierra firme. (Imán et al., 2011).

El uso de la micropropagación, permite introducir rápidamente productos nuevos con una serie de ventajas tales como una mejor sanidad y pureza genética lo que la ha convertido en una técnica muy utilizada en la agricultura en especial en la propagación masiva de plantas ornamentales y frutales. La estrategia para obtener un producto vegetal in vitro óptimo, depende de lograr un sistema que permita la selección de material en campo con excelentes condiciones agronómicas $y$, posteriormente, desarrollar un protocolo de laboratorio que en cada una de sus fases introducción, multiplicación, enraizamiento y endurecimiento, conduzca a producir material vegetal de excelente calidad sanitaria, genética y fisiológica. (Chamorro et al., 2007). La propagación de plantas leñosas a través del cultivo de tejidos, ha sido lograda en varias especies de frutales y forestales cultivadas con el propósito de multiplicar genotipos de interés. El cultivo in vitro es utilizado cada vez más, para la propagación de especies vegetales con el fin de aumentar el número de individuos, superar problemas de fertilidad y de biología reproductiva, así como proporcionar material para su reintroducción en la naturaleza y contribuir a la conservación de la diversidad a mediano y largo plazo. (Sotolongo et al., 2003).
La mayoría de las tecnologías actuales de propagación in vitro, utilizan como base las sales de Murashige y Skoog y diferentes combinaciones de reguladores de crecimiento, propias de la especie objeto de investigación. El objetivo del trabajo, fue establecer un protocolo para el cultivo in vitro de segmentos nodales de "camu camu" Myrciaria dubia (H.B.K) Mc Vaugh.

\section{MATERIALES Y MÉTODOS}

La Colección Nacional de Camu camu del INIA, fue la fuente del material parental utilizándose ramas de la parte apical de plantas adultas, cuyos diámetros estuvieron comprendidos entre 0,8 a $1,2 \mathrm{~cm}$ y $35 \mathrm{~cm}$ de longitud. Las ramas colectadas fueron colocadas en bolsas plásticas, $80-100$ unidades por genotipo; para su transporte al laboratorio. Los trabajos de brotación de estacas se iniciaron con lavados y desinfección con $1 \mathrm{~mL} / \mathrm{L}$ de pinesol por 17 horas, posteriormente se enjuagó con agua y finalmente se cortaron a $30 \mathrm{~cm}$ de tamaño final. Estas ramas fueron sometidas a desinfección con vitavax a dosis de 0,5 g/L por 10 minutos; bajo estas condiciones las ramas se colocaron en tubos ensayos de $25 \mathrm{x}$ $150 \mathrm{~mm}$ conteniendo agua clorada al 0,5\%. La brotación ocurrió entre 20-25 días después del tratamiento. Los segmentos nodales ( $>3$ yemas) que se requiere para la siembra en el medio de cultivo, se obtuvieron a partir del corte de los brotes de estacas en estado de hoja abierta; una vez cortados son depositados en envases de vidrio o plástico conteniendo agua destilada 0 antioxidante PVP a una concentración de $2 \mathrm{~g} / \mathrm{L}$; durante el tiempo que dure la toma de las muestras.

En cámara de flujo laminar, se desinfectó con fungicida Parachupadera 740 PM o Benlate (Benomil) por 10 minutos, luego se aplicó una solución desinfectante de hipoclorito de sodio más la adición de jabón liquido $5 \mathrm{ml} / \mathrm{L}$, por espacio de 10 minutos, luego; tres lavados con agua destilada estéril a 15, 10 y 5 minutos respectivamente.

El establecimiento de los segmentos nodales se realizó utilizando el medio de cultivo basal de Murashige \& Skoog (MS 1962), completo y a la mitad de la concentración final, con 5 $\mathrm{mg} / \mathrm{L}$ AIB, $20 \mathrm{~g} / \mathrm{L}$ sacarosa, 0,25 g/L carbón activado, $7 \mathrm{~g} / \mathrm{L}$ agar y $\mathrm{pH}$ 5,7. Para ello se 
realizaron ensayos de desinfectantes y medios de cultivo, siendo las variables en estudio el porcentaje de supervivencia y contaminación. Los tratamientos fueron:

T1: Hipoclorito $0,0 \%+$ Chupadera $0 \mathrm{~g} / \mathrm{L}$; en $M \& S, M \& S 1 / 2$ y $M \& S+A I B$

T2: Hipoclorito 0,2\% + Chupadera 0,5 g/L; en $M \& S, M \& S 1 / 2$ y $M \& S+A I B$

T3: Hipoclorito $0,3 \%$ + Chupadera $1 \mathrm{~g} / \mathrm{L}$; en $M \& S, M \& S 1 / 2$ y $M \& S+A I B$

T4: Hipoclorito 0,4\% + Chupadera 1,5 g/L; en $M \& S, M \& S 1 / 2$ y $M \& S+A I B$

T5: Hipoclorito 0,5\% + Chupadera $2 \mathrm{~g} / \mathrm{L}$; en $M \& S, M \& S 1 / 2$ y $M \& S+$ AIB.

Luego se ensayaron 04 medios de cultivo para evaluar la supervivencia y el crecimiento de segmentos nodales de camu camu, la distribución de los tratamientos fue la siguiente:

$\mathrm{T} 1: \mathrm{M} \& S+\mathrm{GA} 31,5 \mathrm{mg} / \mathrm{L}+\mathrm{AIA} 5 \mathrm{mg} / \mathrm{L}+$ ANA $0 \mathrm{mg} / \mathrm{L}$

T2: M\&S + GA3 1,5 mg/L + AIA $10 \mathrm{mg} / \mathrm{L}+$ ANA $0 \mathrm{mg} / \mathrm{L}$

T3: M\&S + GA3 1,5 mg/L + AIA $0 \mathrm{mg} / \mathrm{L}+$ ANA $5 \mathrm{mg} / \mathrm{L}$

T4: M\&S + GA3 1,5 mg/L + AIA $0 \mathrm{mg} / \mathrm{L}+$ ANA $10 \mathrm{mg} / \mathrm{L}$
Además, se ensayaron dos medios de cultivo para la multiplicación in vitro de segmentos nodales de camu camu, $\mathrm{T} 1=\mathrm{MS}+0,4 \mathrm{mg} / \mathrm{L}$ BAP y $\mathrm{T} 2=\mathrm{MS}+2,5 \mathrm{mg} / \mathrm{L}$ BAP $+0,1 \mathrm{mg} / \mathrm{L}$ ANA, siendo las variables en estudio el porcentaje de supervivencia y contaminación.

Finalmente se ensayó dos medios de cultivo para enraizamiento in vitro de segmentos nodales de camu camu: MEDIO "A": M\&S completo + Sacarosa $30 \mathrm{~g} / \mathrm{L}+$ Agar $5 \mathrm{~g} / \mathrm{L}+$ C.A 0,5 g/L + AIB $5 \mathrm{mg} / \mathrm{L}$ y MEDIO "B": M\&S completo + Sacarosa $30 \mathrm{~g} / \mathrm{L}+$ Agar $5 \mathrm{~g} / \mathrm{L}+$ C.A $0,5 \mathrm{~g} / \mathrm{L}+$ AIB $10 \mathrm{mg} / \mathrm{L}$; en dos genotipos promisorios de camu camu, MD-014 y MD015, siendo las variables en estudio el porcentaje de supervivencia, contaminación y enraizamiento.

\section{RESULTADOS}

Los tratamientos que presentaron mayores porcentajes de supervivencia en los segmentos nodales de camu camu en la fase de establecimiento fueron el T3 (Hipoclorito $0,3 \%$ + Chupadera $1 \mathrm{~g} / \mathrm{L}$; en M\&S, M\&S $1 / 2$ y $\mathrm{M} \& S+$ AIB) y T5 (Hipoclorito 0,5\% + Chupadera $2 \mathrm{~g} / \mathrm{L}$; en M\&S, M\&S $1 / 2$ y M\&S + AIB), con supervivencia del $100 \%$ de los explantes respectivamente. El tratamiento $\mathrm{T} 1$ (Hipoclorito 0,0\% + Chupadera $0 \mathrm{~g} / \mathrm{L}$; en M\&S, M\&S $1 / 2$ y M\&S + AIB), fue el que presentó el $100 \%$ de contaminación de los explantes (Figura 1).

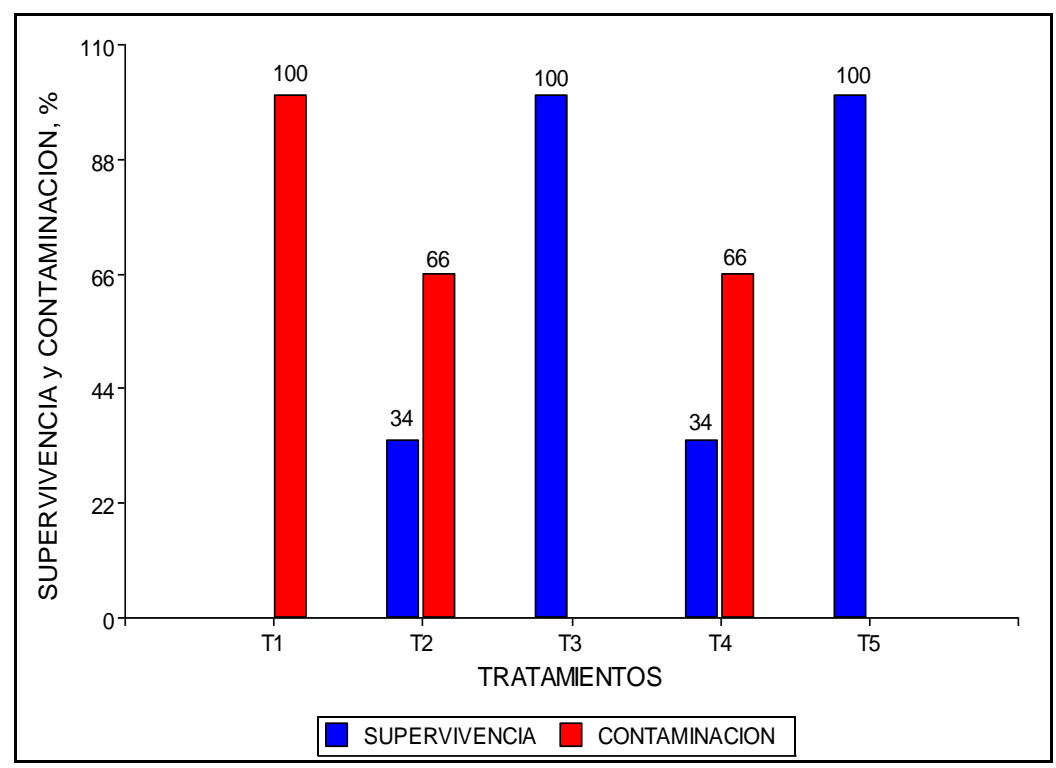

Figura 1. Porcentaje de contaminación y supervivencia en segmentos nodales de camu camu. 
El mejor medio de cultivo para la fase de crecimiento in vitro de segmentos nodales de camu camu es M2 (M\&S + 1,5 mg/L
$\mathrm{GA} 3+10 \mathrm{mg} / \mathrm{L} \mathrm{AIA}$ ), que presentó $72 \%$ de sobrevivencia de segmentos nodales a 45 días después de la siembra (Figura 2).

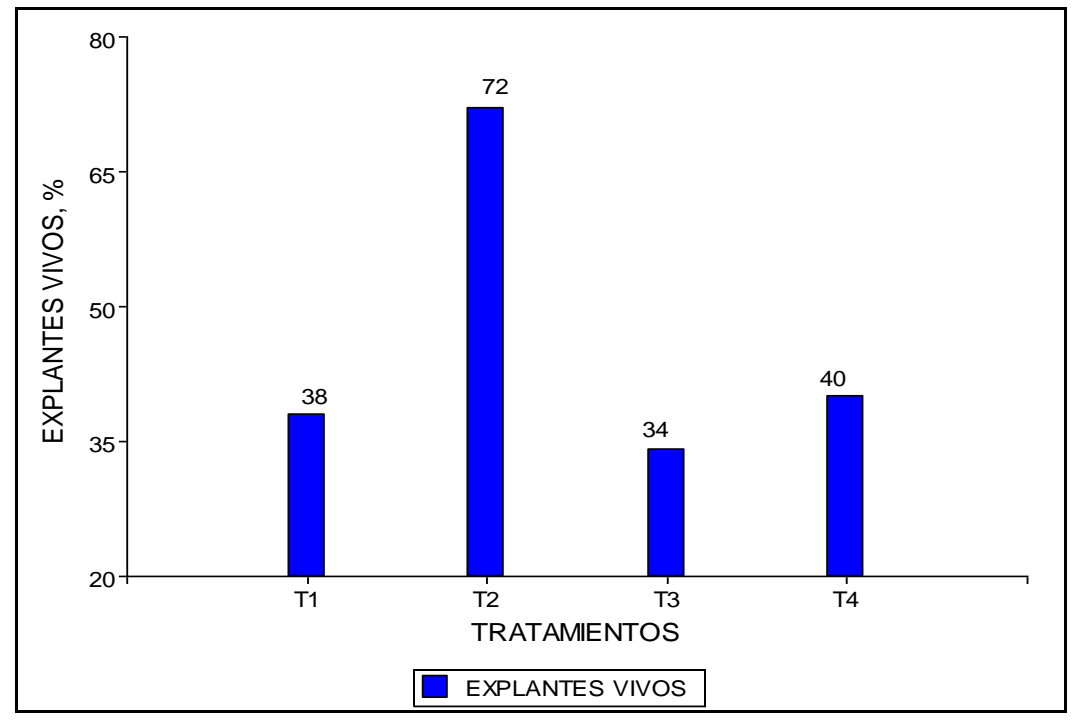

Figura 2. Porcentaje de supervivencia en segmentos nodales de camu camu.

El mejor medio de cultivo para la fase de multiplicación in vitro fue $\mathrm{MS}+2,5 \mathrm{mg} / \mathrm{L}$ BAP $+0,1 \mathrm{mg} / \mathrm{L}$ ANA, que presentó $80 \%$ de supervivencia de segmentos nodales a los 30 días después del subcultivo y emisión de nuevos brotes de crecimiento lento.

Para medios de cultivo evaluados a los 14 días después del subcultivo, se encontró en el Medio A, genotipo MD-014; 85,71\% y MD015; 71,4\% de supervivencia. Para el Medio B, genotipo MD-014, 93\% y MD-015; 71,4\% de supervivencia de segmentos nodales. No hubo enraizamiento, en los segmentos nodales.

\section{DISCUSIÓN}

Los porcentajes de supervivencia de segmentos nodales de camu camu, son similares a los resultados encontrados por Chinchilla (2008), quien trabajó con "sapote", indicando que los niveles de contaminación en plantas provenientes de ambientes controlados fueron menores a nivel de segmentos nodales, al igual que la diversidad de microorganismos fue considerablemente menor. Estos resultados permiten pensar que los tejidos se encontraban más sanos y libres de saprofitos debido a que las plantas de donde se tomaron los explantes estuvieron bajo condiciones ambientales controladas con aplicaciones periódicas de agua, fungicidas, abono foliar y bajo techo; lo que favorece una mayor sanidad. Asimismo, indica que bajo estas condiciones el desarrollo de las plantas suele ser más homogéneo. No obstante, se observó la aparición de hongos y bacterias que sobrevivieron a la desinfección y que se mostraron después de un mes de cultivo (sin realizar subcultivos).

Ramírez (1999), menciona que la presencia de microorganismos contaminantes, hongos y bacterias; es uno de los principales problemas durante el establecimiento in vitro de explantes procedentes de plantas leñosas, sobretodo de condición adulta y cultivadas directamente en el campo.

Corbino (2000), afirma que, en las especies leñosas, la lignina, es un compuesto orgánico que impregna las paredes de los vasos de conducción. Estas especies presentan, en su mayoría, resistencia al ser multiplicadas in vitro. 

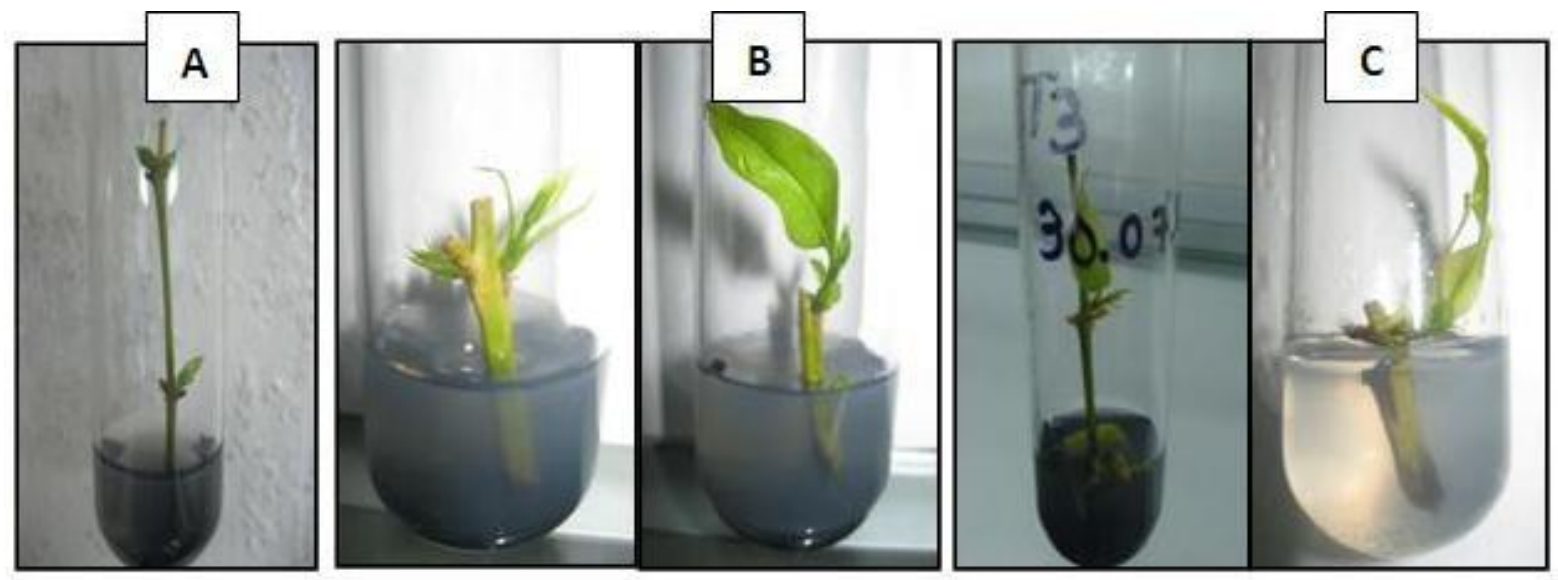

Figura 3. Propagación vegetativa por cultivo in vitro del camu camu, A) Establecimiento, B) Crecimiento, C) Multiplicación

\section{CONCLUSIONES}

Los tratamientos que presentaron $100 \%$ de supervivencia en los segmentos nodales de camu camu en la fase de establecimiento, fueron Hipoclorito de sodio $0,3 \%+$ fungicida Parachupadera $1 \mathrm{~g} / \mathrm{L}$, en M\&S, M\&S $1 / 2$ y M\&S + AIB, y Hipoclorito de sodio $0.5 \%+$ fungicida Parachupadera $2 \mathrm{~g} / \mathrm{L}$, en M\&S, M\&S $1 / 2$ y $M \& S+A I B$. El mejor medio de cultivo para la fase de crecimiento in vitro de segmentos nodales de camu camu, fue el $\mathrm{M} \& \mathrm{~S}+1,5 \mathrm{mg} / \mathrm{L} \mathrm{GA} 3+10 \mathrm{mg} / \mathrm{L}$ AIA, por presentar $72 \%$ de sobrevivencia de segmentos nodales a los 45 días después de la siembra. El mejor medio de cultivo para la fase de multiplicación in vitro fue $M S+2,5$ $\mathrm{mg} / \mathrm{L}$ BAP $+0,1 \mathrm{mg} / \mathrm{L}$ ANA, que presentó $80 \%$ de supervivencia de segmentos nodales a los 30 días después del subcultivo y emisión de nuevos brotes de crecimiento lento. No hubo enraizamiento de los segmentos nodales para los medios de cultivo evaluados.

\section{REFERENCIAS}

Corbino G. 2000. Micropropagación de especies leñosas. EEA. San Pedro, INTA. Buenos Aires Argentina.

Chamorro AH, Martínez SL, Fernández JC, Mosquera T. 2007. Evaluación de diferentes concentraciones de algunos reguladores de crecimiento en la multiplicación y enraizamiento in vitro de Limonium var. Misty blue Agronomía Colombiana 25(1), 47-53.
Chinchilla SI. 2008. Establecimiento y cultivo in vitro de Pouteria sapota (Jacquin) H. E. Moore \& Stearn. Trabajo final de graduación. Universidad de Costa Rica. 74 pp.

Imán SA, Pinedo SF, Melchor MJ. 2011. Caracterización morfológica y evaluación de la colección nacional de germoplasma de camu camu Myrciaria dubia (H.B.K.) Mc. Vaugh, del INIA Loreto-Perú. Revista Scientia Agropecuaria 2, 189-201.

Murashige T \& Skoog F. 1962. A revised médium for rapid growth and bioassays with Tobacco tissue culture. In: Physiology Plantarum 15(3), 473 - 497.

Pinedo SF. 2010. Ensayo clonal de cinco (05) genotipos promisorios de Camu camu Myrciaria dubia (H.B.K.) Mc. Vaugh; efecto sobre su rendimiento y características agronómicas; en suelos no inundables del Campo Experimental El Dorado Km. 25 carretera Iquitos-Nauta. Tesis Maestría. Escuela de Post Grado de la Universidad Nacional de la Amazonía Peruana. $96 \mathrm{p}$.

Ramírez VM, León SS, Urdaneta FA. 1999. Evaluación de desinfectantes superficiales en el establecimiento in vitro de psidium guajava L. y Psidium friedrichthalianum. Rev Fac Agron (LUZ) 16, 243-255.

Sotolongo, R. S., et. al.; 2003. Micropropagación de Psidium salutare (Myrtaceae). Revista del Jardín Botánico Nacional 24(1-2), 245 - 250. 